\title{
MICROBIOTA INFECTANTE DE FERIDAS CIRÚRGICAS: ANÁLISE DA PRODUÇÃO CIENTÍFICA NACIONAL E INTERNACIONAL
}

\author{
Surgical wounds infective microbiota: national and international analysis of scientific production
} Microbiota infeccioso de las heridas quirúrgicas: análisis de la producción científica nacional e internacional

\author{
Wanderlei Barbosa dos Santos', Maria Gabriella Silva Araujo², Jeferson Caetano da Silva', Thaís Honório Lins Bernardo³, \\ Maria Lysete de Assis Bastos ${ }^{4}$, Regina Célia Sales Santos Veríssimo ${ }^{3}$
}

RESUMO: Objetivo: Identificar a microbiota de feridas operatórias infectadas descritas em produções científicas. Método: Revisão integrativa realizada em bases de dados: Literatura Latino-Americana e do Caribe em Ciências da Saúde, Medical Literature Analysis and Retrieval System Online, Scientific Electronic Library Online, Cochrane e SciFinder Scholar. Para a seleção dos artigos foram utilizadas cinco palavras-chaves contempladas nos Descritores em Ciências da Saúde e os operadores booleanos OR e AND. Utilizou-se formulário com informações: identificação dos artigos, objetivo, tipo de estudo e resultados. Resultados: Foram selecionados 56 artigos, publicados entre 1960 e 2013. Os principais microrganismos infectantes foram as bactérias, seguidas pelos fungos. Infecções foram causadas principalmente por: Staphylococcus aureus (39,3\%), Escherichia coli (30,4\%), Pseudomonas aeruginosa (19,6\%), Staphylococcus epidermidis (17,8\%), Klesbsiella spp (12,5\%) e Enterobacter spp (10,7\%). Conclusão: Bactérias Gram-negativas são os mais frequentes microrganismos infectantes de feridas cirúrgicas. Contudo, Staphylococcus aureus é o microrganismo de maior frequência.

Palavras-chave: Bactérias. Infecções por protozoários. Vírus. Fungos. Infecção da ferida operatória.

ABSTRACT: Objective: to identify the microbial flora of infected surgical wounds described in scientific literature. Method: integrative review conducted in the following databases: Literatura Latino-Americana e do Caribe em Ciências da Saúde, Medical Literature Analysis and Retrieval System Online, Scientific Electronic Library Online, Cochrane, and SciFinder Scholar. Five keywords from the Health Sciences Descriptors and boolean operators "OR" and "AND" were used for the selection of articles. A form with the information was completed: article identification, purpose, type of study, and results. Results: A total of 56 papers were selected, published between 1960 and 2013. The main infectious microorganisms were bacteria, followed by fungi. Infections were primarily caused by Staphylococcus aureus (39.3\%), Escherichia coli (30.4\%), Pseudomonas aeruginosa (19.6\%), Staphylococcus epidermidis (17.8\%), Klesbsiella spp (12.5\%) and Enterobacter spp (10.7\%). Conclusion: Gram-negative bacteria are the most common infectious microorganisms in surgical wounds. However, Staphylococcus aureus is the most frequent microorganism.

Keywords: Bacteria. Protozoan infections. Viruses. Fungi. Surgical wound infection.

RESUMEN: Objetivo: Identificar flora microbiana de heridas quirúrgicas infectadas descritas en producción científica. Método: Revisión integradora realizada en las bases de datos: Literatura Latino-Americana e do Caribe Ciências da Saúde, Medical Literature Análise e Retrieval System on-line, Scientific Electronic Library Online, Cochrane e SciFinder Scholar. La selección se utilizó cinco palabras clave que se contemplan en Ciencias de la Salud y operadores booleanos “OR” y “AND”. Utilizó formulario con información: la identificación del papel, propósito, tipo de estudio y resultados. Resultados: 56 documentos fue seleccionado con la publicación entre 1960 y 2013. Principales microorganismos infecciosos era bacterias, seguidos por hongos. Infecciones fueron causadas principalmente por Staphylococcus aureus (39,3\%), Escherichia coli (30,4\%), Pseudemonas aeruginosa (19,6\%), Staphylococcus epidermidis (17,8\%), Klesbsiella spp (12,5\%) y Enterobacter spp (10,7\%). Conclusión: bacterias Gram-negativas son microorganismos infecciosos más comunes de heridas quirúrgicas. Staphylococcus aureus es el microorganismo más frecuente.

Palabras clave: Bacterias. Infecciones por protozoos. Virus. Hongos. Infección de herida operatoria.

'Graduando em Enfermagem pela Universidade Federal de Alagoas (UFAL). E-mail: wanderley89@live.com; jefer_caetano@hotmail.com

${ }^{2}$ Enfermeira pela UFAL. E-mail: gabriellaaraujo2@hotmail.com

${ }^{3}$ Doutora em Biotecnologia pela Rede Nordeste de Biotecnologia (RENORBIO). Professora Adjunta no curso de Graduação em Enfermagem da UFAL. E-mail: thais.bernardo@esenfar.ufal.br; salesregina@hotmail.com Escola de Enfermagem e Farmácia da Universidade Federal de Alagoas - Avenida Lourival Melo Mota, s/n - Tabuleiro dos Martins - CEP: $57072-900$ - Maceió (AL), Brasil.

4Doutora em Química e Biotecnologia. Professora Adjunta III da UFAL. E-mail: lysetebastos@gmail.com

Recebido: 02 dez. 2015 - Aprovado: 23 mar. 2016

DOI: $10.5327 / Z 1414-4425201600010007$ 


\section{INTRODUÇÃO}

A infecção hospitalar, segundo a Portaria n ${ }^{\circ} 2616 / 98$ do Ministério da Saúde, é definida como aquela adquirida após admissão do paciente e que se manifesta durante a internação ou após a alta, quando relacionada com a internação ou a procedimentos hospitalares/ambulatoriais ou as manifestadas antes de 72 horas da internação, porém associadas a procedimentos diagnósticos e/ou terapêuticos, realizados durante esse período ${ }^{1}$.

Atualmente, devido à alta taxa de morbidade e mortalidade, a infecção de ferida operatória é motivo de grande preocupação nos hospitais, podendo também causar danos físicos e emocionais, afastando muitas vezes o cliente do trabalho e do convívio social. Isso também faz aumentar os custos com tratamentos, o que repercute na maior permanência do indivíduo no ambiente hospitalar, e no acréscimo dos gastos médico-hospitalares².

A infecção de sítio cirúrgico (ISC) pode ser compreendida como a entrada, o estabelecimento e a multiplicação do patógeno na incisão cirúrgica. O indivíduo pode apresentar queda do estado geral, anorexia, febre, drenagem purulenta, deixando clara a infecção por microrganismo. A despeito de sua natureza pouco específica, a febre é o sinal clínico inicial mais comum de infecção ${ }^{3}$.

Geralmente, a infecção da ferida operatória pode ocorrer entre 4 e 6 dias após o procedimento, no entanto, de acordo com o Centro de Controle de Doenças dos Estados Unidos (CDC), $98 \%$ da ISC pode se manifestar até 30 dias após a cirurgia, ou mesmo 1 ano mais tarde, quando trata-se de prótese implantada ${ }^{4}$.

Alguns fatores propiciam o estabelecimento e a gravidade das infecções, podendo ser intrínsecos - quando relacionados com as condições do paciente, sendo eles: diabetes melittus, obesidade, desnutrição, enfermidade vascular crônica, extremos de idade, esgotamento proteico e tabagismo ${ }^{5}$ - , bem como extrínsecos, que devem ser identificados no pré-operatório e são relacionados à cirurgia e ao ambiente hospitalar, como por exemplo, a duração da lavagem cirúrgica, hospitalização prolongada, raspagem, duração da cirurgia, antissepsia da pele, antibióticos profiláticos e esterilização ${ }^{6}$.

O CDC classifica a ISC como incisional superficial ou profunda, ou ISC de órgão/espaço. A infecção superficial envolve pele e tecido subcutâneo, e a profunda, as camadas mais profundas como fáscia muscular. Enquanto que a ISC órgão/espaço envolve qualquer parte da anatomia além da incisão que foi manipulada ou aberta pelo cirurgião ${ }^{4}$.

No Brasil, a ISC ocupa a terceira posição entre todas as infecções presentes em serviços de saúde e abrange de 14 a $16 \%$ das infecções em pacientes hospitalizados, sendo que $93 \%$ dessas são graves, chegando a invadir órgãos ou espaços acessados durante o procedimento cirúrgico, tendo assim uma taxa de incidência de $11 \%{ }^{3}$. As estimativas das ISC apresentam uma incidência de $2,3 \%$, e dependem do tipo de vigilância realizada, das particularidades do hospital, do paciente e do procedimento cirúrgico ${ }^{7}$.

Evidencia-se que a ISC pode estar relacionada com a presença de microrganismos, sendo as bactérias as que mais afetam as incisões cirúrgicas. Alguns desses patógenos fazem parte da própria flora da pele em condições normais, no entanto, tornam-se patogênicos em condições favoráveis para sua proliferação, causando assim as ISC ${ }^{8}$.

Como estratégia para prevenção de ISC, realiza-se a antibioticoterapia profilática, no entanto, muitas bactérias presentes no ambiente hospitalar tornaram-se resistentes à maioria dos antibióticos utilizados no perioperatório devido à exposição a esses fármacos, aumentando os custos do hospital, assim como prejudicando a recuperação do paciente .

Diante do que foi exposto, esta revisão tem como questão norteadora: qual a microbiota infectante das feridas cirúrgicas descritas nas produções científicas?

\section{OBJETIVO}

Identificar nas produções científicas nacionais e internacionais a microbiota presente nas infecções de feridas operatórias.

\section{MÉTODO}

Trata-se de uma revisão integrativa, que consiste numa ferramenta importante para a prática clínica, a qual consegue reunir resultados de determinado tema e proporcionar um aprofundamento do tema investigado.

A pesquisa foi realizada nas seguintes bases de dados: Literatura Latino-Americana e do Caribe em Ciências da Saúde (LILACS), Medical Literature Analysis and Retrieval System Online (MEDLINE), Cochrane, e as bibliotecas virtuais Scientific Electronic Library Online (SciELO) e SciFinder Scholar, 
tendo como questão norteadora a microbiota infectante das feridas cirúrgicas.

O estudo foi realizado entre os meses de setembro e dezembro de 2013, sem recorte temporal. Para a seleção dos artigos foram utilizadas as palavras-chave em português: bactérias; protozoários, vírus, fungos e infecção de ferida operatória; em inglês: bacterias, protozoan, viruses, fungi, surgical wound infection; e em espanhol: bacterias, protozoos, virus, hongos, infección de herida operatória; contempladas nos Descritores em Ciências da Saúde (DeCS).

Foram utilizados os operadores booleanos OR e AND, e foi usado como estratégias de pesquisa o cruzamento dos descritores em português, inglês e espanhol, tais como (bactérias OR protozoários OR vírus OR fungos) AND (infecção de ferimento pós-operatório OR infecção da ferida operatória OR infecção de ferida pós-operatória).

Os critérios de inclusão definidos para a seleção foram: artigos publicados em português, inglês e espanhol e que retrataram na íntegra a temática do estudo. Os artigos que não se relacionam com a infecção da ferida cirúrgica e estudos duplicados foram excluídos. Os estudos encontrados em mais de uma base de dados foram considerados somente uma vez.

Para analisar os artigos, foram selecionadas as variáveis do título dos artigos, autores, país, periódico, base de dados, ano de publicação, qualificação dos autores, idioma, área profissional, tipo de abordagem, tipo de estudo, classificação das cirurgias e os tipos de cirurgias infectadas.

Os artigos que atenderam aos critérios de inclusão foram analisados, através de um formulário que contemplou informações de identificação do artigo, a fim de consolidar todos os resultados apresentados nas produções científicas.

\section{RESULTADOS}

Foram encontrados 278 artigos com a busca nas base de dados, dentre esses, 56 artigos atenderam aos critérios da pesquisa. O perfil bibliométrico dos 56 estudos incluídos na revisão foi traçado e está apresentado na Tabela 1.

A maioria dos estudos foi de abordagem quantitativa $(94,6 \%)$ e dentre esses predominaram os estudos do tipo descritivo exploratório ( $85,7 \%$ ), sendo que $71,4 \%$ foram publicados em revistas com distribuição internacional.

Em relação à temática geral, todos os artigos tratavam de diferentes cirurgias que apresentaram infecção em seu sítio cirúrgico. As cirurgias foram classificadas e identificadas de acordo com sua localização como mostra na Tabela 2.
A microbiota responsável pela infecção dessas cirurgias também foi identificada, analisada e os principais microrganismos infectantes das feridas operatórias descritas nas produções científicas foram as bactérias, seguidas pelos fungos (Tabelas 3 e 4 ).

Tabela 1. Perfil bibliométrico dos estudos analisados.

\begin{tabular}{|l|c|}
\hline Variável & $\mathbf{n}(\%)$ \\
\hline Base de dados & \\
\hline Cochrane & $29(51,8)$ \\
\hline LILACS & $25(44,6)$ \\
\hline SciELO & $2(3,6)$ \\
\hline Continentes & \\
\hline América do Norte & $13(23,21)$ \\
\hline América Central & $5(8,92)$ \\
\hline América do Sul & $20(35,71)$ \\
\hline Europa & $11(19,64)$ \\
\hline Ásia & $7(12,5)$ \\
\hline Décadas & \\
\hline $1960-1969$ & $1(1,80)$ \\
\hline $1970-1979$ & $2(3,60)$ \\
\hline $1980-1989$ & $11(19,6)$ \\
\hline $1990-1999$ & $8(14,3)$ \\
\hline $2000-2009$ & $22(39,3)$ \\
\hline $2010-2013$ & $12(21,43)$ \\
\hline Referências & \\
\hline Internacionais & $40(71,4)$ \\
\hline Nacionais & $16(28,6)$ \\
\hline Formação acadêmica & \\
\hline Médico & $153(62,4)$ \\
\hline Enfermeiro & $8(3,3)$ \\
\hline Odontólogo & $8(3,3)$ \\
\hline Farmacêutico & $3(1,2)$ \\
\hline Não especificada & $73(29,8)$ \\
\hline Abordagem & $53(9,1)$ \\
\hline Quantitativa & $3(5,4)$ \\
\hline Qualitativa & \\
\hline Descritivo exploratório & \\
\hline Estudo de revisão & \\
\hline Experimental & \\
\hline Relato de experiência & \\
\hline
\end{tabular}


Tabela 2. Classificação e identificação dos tipos de cirurgias encontradas nos estudos analisados.

\begin{tabular}{|l|c|}
\hline Variável & $\mathbf{n ~ ( \% )}$ \\
\hline Classificação das cirurgias & \\
\hline Profunda & $32(37,6)$ \\
\hline Superficial & $32(37,6)$ \\
\hline Órgão/espaço & $21(24,8)$ \\
\hline Tipos de cirurgias infectadas & \\
\hline Trato digestivo & $27(31,73)$ \\
\hline Cardiotorácica & $15(17,64)$ \\
\hline Ortopédica & $15(17,64)$ \\
\hline Cabeça e pescoço & $9(10,6)$ \\
\hline Abdominal & $9(10,6)$ \\
\hline Urológica & $1(1,17)$ \\
\hline Não especificadas & $9(10,58)$ \\
\hline
\end{tabular}

Tabela 3. Percentual de infecção do sítio cirúrgico, por bactérias Gram-positivas, identificado nas publicações científicas.

\begin{tabular}{|l|c|}
\hline Microrganismos & $\%$ \\
\hline Staphylococcus aureus & 39,28 \\
\hline Staphylococcus epidermidis & 17,85 \\
\hline Staphylococcus coagulase-negativo & 10,71 \\
\hline Staphylococcus spp & 12,50 \\
\hline Staphylococcus haemolyticus & 3,57 \\
\hline Staphylococcus saprophyticus & 1,78 \\
\hline Staphylococcus capitis & 1,78 \\
\hline Staphylococcus pyogenes & 1,78 \\
\hline Staphylococcus hominis & 1,78 \\
\hline Streptococcus viridans & 3,57 \\
\hline Streptococos pneumoniae & 1,78 \\
\hline Streptococcus pyogenes & 1,78 \\
\hline Streptococos spp & 5,35 \\
\hline Corynebacterium minutissimum & 1,78 \\
\hline Corynebacterium bovis & 1,78 \\
\hline Corinebactérias & 1,78 \\
\hline Clostridium innocuum & 1,78 \\
\hline Enterococcus spp & 10,71 \\
\hline Enterococos faecalis & 7,14 \\
\hline Peptococcus sp & 3,57 \\
\hline Peptostreptococci & 7,14 \\
\hline Propionibacterium spp & 1,78 \\
\hline Propionibacterium acnes & 3,57 \\
\hline Pneumococo sp & 1,78 \\
\hline Eubacterium lentum & 1,78 \\
\hline
\end{tabular}

Tabela 4. Percentual de infecção do sítio cirúrgico, por bactérias Gram-negativas, identificado nas publicações científicas.

\begin{tabular}{|c|c|}
\hline Microrganismos & $\%$ \\
\hline Acinetobacter baumanii complex & 3,57 \\
\hline Acinetobacter baumannii & 1,78 \\
\hline Acinetobacter spp & 3,57 \\
\hline Acinetobacter calcoaceticus & 5,35 \\
\hline Bacteroides fragilis & 7,14 \\
\hline Bacteroides spp & 7,14 \\
\hline Bacillus sp & 1,78 \\
\hline Cedecea lapager & 1,78 \\
\hline Escherichia coli & 30,35 \\
\hline Enterobacter spp & 10,71 \\
\hline Enterobacter cloacae & 7,14 \\
\hline Enterobacter aerogenes & 1,78 \\
\hline Klensiella spp & 12,5 \\
\hline Klebsiella pneumoniae & 5,35 \\
\hline Klebsiella ornithiolytica & 1,78 \\
\hline Klebsiella oxytoca & 1,78 \\
\hline Morganela morganii & 8,92 \\
\hline Mycobacterium massiliense & 1,78 \\
\hline Mycobacterium abscessus & 1,78 \\
\hline Mycobacterium chelonae & 1,78 \\
\hline Mycobacterium fortuitum & 1,78 \\
\hline Melaniogenicus bacillus & 1,78 \\
\hline Micrococcus luteus & 1,78 \\
\hline Pseudomonas aeruginosa & 19,64 \\
\hline Pseudomonas epiderme & 1,78 \\
\hline Pseudomonas sp & 5,35 \\
\hline Proteus spp & 3,57 \\
\hline Proteus mirabilis & 7,14 \\
\hline Proteus vulgaris & 3,57 \\
\hline Serratia marcescens & 3,57 \\
\hline Serratia spp & 3,57 \\
\hline Sphingomonas paucimobilis & 1,78 \\
\hline Salmonella sp & 1,78 \\
\hline Veillonella & 3,57 \\
\hline Haemophilus influenzae & 3,57 \\
\hline Fusobacterium & 1,78 \\
\hline Moraxella & 1,78 \\
\hline Thetaiotaomicron cacteroides & 1,78 \\
\hline
\end{tabular}


As infecções mais citadas nas publicações científicas foram causadas principalmente por: Staphyilococcus aureus $(39,28 \%)$, Escherichia coli (30,35\%), Pseudomonas aeruginosa (19,64\%), Staphylococcus epidermidis (17,85\%), Klesbsiella spp (12,50\%), Enterobacter spp (10,71\%), Morganela morganii $(8,92 \%)$ e Bacteroides spp $(7,14 \%)$. Observa-se que o principal microrganismo nas infecções das feridas cirúrgicas foram as bactérias Gram-negativas, que possuem uma tendência à resistência à terapia empregada.

\section{DISCUSSÃO}

Embora existam progressos com o desenvolvimento da antibioticoterapia no tratamento das infecções hospitalares, observa-se que as infecções das incisões cirúrgicas permanecem sendo motivo de preocupação, principalmente quando ocorre deiscência da ferida operatória ${ }^{10}$.

A infecção por microrganismos no sítio cirúrgico tornase cada vez mais um problema de saúde, principalmente as infecções causadas por Escherichia coli, Staphylococcus aureus e Pseudomonas aeruginosa, que podem causar deiscência cirúrgica completa sem evisceração, abscesso, retardamento no processo de cicatrização e óbito por choque séptico e / ou pneumonia ${ }^{11}$.

A destituição e o crescimento bacteriano são os principais pré-requisitos para desenvolvimento de uma infecção, assim como o tipo de microrganismo e as toxinas sintetizadas por eles. Vários patógenos possuem componentes específicos que aumentam a sua virulência, a exemplo das cápsulas de Klebsiella spp e do Streptococcus pneumoniae, as endotoxinas das bactérias Gram-negativas Pseudomonas sp, Acinetobacter baumannii, Bacillus sp, as exotoxinas dos estreptococos, o biofilme dos Staphylococcus aureus e dos Staphylococcus epidermidis, que contribuem para a resistência aos antibióticos ${ }^{12}$.

Dos patógenos Gram-positivos, o Staphylococus aureus é responsável por muitas das infecções hospitalares que, geralmente, são transmitidas por contato direto ou indireto, da própria flora normal da pele do paciente ou migração durante a consumação dos procedimentos. Em muitos casos também pode apresentar alta resistência a antibióticos. Sua gravidade e ocorrência dependem essencialmente da tríplice relação: susceptibilidade do hospedeiro, resistência e quantidade de microrganismo ${ }^{13}$.

Estudos demonstram que os patógenos da microbiologia das ISC variam, dependendo do tipo de operação e dos procedimentos realizados. O Staphylococcus aureus foi o microrganismo isolado que mais predominou em ISCs, seguido da Klebisiella pneumoniae, da Escherichia coli e da Klebsiela ozonae ${ }^{14}$.

Alguns autores identificaram em suas pesquisas 343 colonizações bacterianas (média de 1,5 por paciente), por 13 microrganismos resistentes diferentes, e os 5 mais comuns representaram mais de $90 \%$ dos casos (Acinetobacter baumannii, 36,3\%; Pseudomonas aeruginosa, 21,9\%; Staphylococcus aureus resistente à meticilina, 14,7\%; Klebsiella pneumonia, 11\%; e Escherichia coli, 7,8\%). Porém, isso não denota que as infecções foram causadas pelos microrganismos resistentes isolados, somente que as colonizações foram em muitos casos associadas à presença dos mesmos ou de outros microrganismos nas infecções desenvolvidas ${ }^{15}$.

Evidenciaram-se outros microrganismos que não eram resistentes, no entanto, demonstraram capacidade de serem responsáveis por infecções hospitalares, sendo os mais comuns Candida albicans (18,5\%), Escherichia coli (15,1\%), Pseudomonas aeruginosa (8,9\%), Enterobacter cloacae (8,2\%) e Enterococcus faecalis $(8,2 \%)$. Entre os microrganismos resistentes mais comuns causadores de infecção hospitalar estão Acinetobacter baumannii (35,1\%), Pseudomonas aeruginosa (21,6\%), Klebsiella pneumonia e Escherichia coli $(10,8 \%)^{15}$.

Embora as bactérias Gram-positivas sejam os principais agentes causais, existem grandes variações, e cada serviço deve conhecer a microbiota relacionada com a assistência à saúde. Outros agentes, além dos germes, são os contaminantes provenientes de várias fontes exógenas, como instrumentos e próteses ${ }^{16}$.

No que se refere à determinação do local específico da ISC, a amostra apresentou que as categorias superficial e profunda apresentaram o mesmo quantitativo, seguidas pela de órgão e espaço, tanto intra-hospitalar como após a alta. Com isso, durante o período de internação registrou-se na categoria superficial e profunda $37,6 \%$ das infecções e para a de órgão ou cavidade $24,8 \%$. Esses resultados não corroboram outros estudos realizados, nos quais foram registrados $87,5 \%$ em ISC superficial e $12,5 \%$ profunda, não havendo nenhum registro de ISC de órgão ou cavidade. O mesmo estudo ainda apresenta que no pós-alta a totalidade da ISC foi diagnosticada sendo $91,6 \%$ na classificação superficial, $4,2 \%$ para profunda e $4,2 \%$ de órgão/ cavidade $^{17}$.

Sabe-se que a ISC é multifatorial, sendo assim, com o propósito de diminuir os índices de ISC, medidas profiláticas devem ser dotadas, como a degermação cirúrgica das mãos e antebraços, justificada pela taxa de perfuração das luvas ao final da cirurgia, de $66,7 \%$, sendo que nas cirurgias essas perfurações não são observadas pelos profissionais ao término do 
procedimento. Outras medidas também podem ser tomadas, tais como o momento apropriado para a remoção do pelos, quando necessário; profilaxia antimicrobiana em relação à escolha e ao tempo de administração do agente; não usar acessórios em mãos ou antebraços por equipes de cirurgiões e o uso adequado de máscara cirúrgica, casaco/vestido estéreis ${ }^{18}$.

Investir na educação com o intuito de aprimorar a assistência e o envolvimento dos profissionais na execução das medidas preventivas de ISC são primordiais para a incorporação integral das recomendações contra a ISC no atendimento ao paciente cirúrgico ${ }^{19}$.

\section{CONCLUSÃO}

Diante dos artigos analisados constatou-se que as cirurgias realizadas no trato digestivo, seguidas pelas cirurgias cardiotorácicas e ortopédicas, são os procedimentos que mais possuem infecções em seu sítio cirúrgico.

As bactérias Gram-negativas foram os microrganismos mais citados nos artigos estudados como responsáveis pela infecção das incisões cirúrgicas, no entanto, a espécie Staphylococcus aureus foi o microrganismo mais presente nas incisões cirúrgicas infectadas descritas nas publicações científicas analisadas.

\section{REFERÊNCIAS}

1. Brasil. Ministério da Saúde. Portaria n².616, de 12 de maio de 1998. Regulamenta as ações de controle de infecções hospitalares no Brasil. Brasília: Diário Oficial da União; 1998 [acesso em 2014 mar 14]. Disponível em: http://www.ccih.med.br/portaria2616.html

2. Silva QCG, Barbosa MH. Fatores de risco para infecção de sítio cirúrgico em cirurgia cardíaca. Acta Paul Enferm. 2012;25(Núm Especial):89-95.

3. Brasil. Agencia Nacional de Vigilância Sanitária. Sítio cirúrgico: critérios nacionais de infecções relacionadas à assistência à saúde. Brasília: ANVISA; 2009.

4. Mangram AJ, Horan TC, Pearson ML, Silver LC, Jarvis WR. Guideline for prevention of surgical site infection, 1999. Centers for Disease Control and Prevention (CDC) Hospital Infection Control Practices Advisory Committee. Am J Infect Control. 1999;27(2):97-132.

5. Oliveira EM, Paula JB. Fatores associados à infecção de sítio cirúrgico em pacientes idosos submetidos à cirurgia cardíaca com esternotomia. Saúde (Sta Maria). 2014;40(1):37-44.

6. Feitosa RGF, Fernandes FAM, Narciso Junior J, Araújo Junior ON, Costa FA, Cavalcante LDW. Análise da incidência de infecção de sítio cirúrgico em cirurgias oncológicas do aparelho digestivo no Hospital Geral de Fortaleza. Medicina (Ribeirão Preto). 2014;47(2):157-64.

7. Ren T, Ding L, Xue F, He Z, Xiao H. Risk factors for surgical site infection of pilon fractures. Clinics. 2015;70(6):419-22.

8. Santos GC, Baylão AFG, Borges SCF, Silva LA, Batista MHJ, Leite GR. Incidência e fatores de risco de infecção de sítio cirúrgico: revisão integrativa. IR. 2015;11(1):1-17.

9. Pereira GCB, Lima LS, Pinheiro PNQ, Dolabela MF. Perfil de uso de antimicrobianos em procedimentos de otorrinolaringologia. Rev Para Med. 2014;28(1):31-9.

10. Santana RS, Viana AC, Santiago JS, Menezes MS, Lobo IMF, Marcellini PS. Consequências do uso excessivo de antimicrobianos no pós-operatório: o contexto de um hospital público. Rev Col Bras Cir. 2014;41(3):149-54.

11. Alves ANF, Duartes CA, Paula MP, Moraes RE, Coutinho RMC. Conhecimento da enfermagem na prevenção de infecção hospitalar. Rev Inst Ciênc Saúde. 2007;25(4):365-72.

12. Lichtenfels E, Lucas ML, Webster R, d'Azevedo PA. Profilaxia antimicrobiana em cirurgia vascular periférica: cefalosporina ainda é o padrão-ouro? J Vasc Bras. 2007;6(4):378-87.

13. Vilarinho LM, Vilarinho MLCM, Silva FL, Guimaraes MSO, Leal ACAM. Isolamento de Staphylococcus aureus em mãos de profissionais de unidades de terapia intensiva. Rev Pre Infec e Saúde. 2015;1(1):10-18.

14. Rodrigues AL, Simoes MLPB. Incidência de infecção do sítio cirúrgico com o preparo pré-operatório utilizando iodopolividona $10 \%$ hidroalcoólica e clorexidina alcoólica 0,5\%. Rev Col Bras Cir. 2013;40(6):443-8.

15. Oliveira AC, Kovner CT, Silva RS. Infecção hospitalar em unidade de tratamento intensivo de um hospital universitário brasileiro. Rev Latino-Am Enfermagem. 2010;18(2):233-9.

16. Ercole FF, Chianca TCM, Duarte D, Starling CEF, Carneiro M. Infecção de sítio cirúrgico em pacientes submetidos a cirurgias ortopédicas: 0 índice de risco NNIS e predição de risco. Rev Latino-Am Enfermagem. 2011;19(2):269-76.

17. Oliveira AC, Ciosak SI. Infecção de sítio cirúrgico em hospital universitário: vigilância pós-alta e fatores de risco. Rev Esc Enferm USP. 2007;41(2): 258-63.

18. Oliveira AC, Gama CS. Avaliação da adesão às medidas para a prevenção de infecções do sítio cirúrgico pela equipe cirúrgica. Rev Esc Enferm USP. 2015;49(5):767-74.

19. Pereira BRR, Mendoza IYQ, Couto BRGM, Ercole FF, Goveia VR. Artroplastia do quadril: prevenção de infecção do sítio cirúrgico. Rev SOBECC. 2014;19(4):181-7. 